Бобрышов Сергей Викторович, Джегутанова Наталья Ивановна

\title{
СМЫСЛЫ, ЦЕЛИ И ФУНКЦИИ СОВРЕМЕННОЙ РОССИЙСКОЙ АСПИРАНТУРЫ: ПРОБЛЕМНЫЙ АНАЛИЗ
}

В статье рассматриваются различные аспекты понимания современной модели российской аспирантуры как уровня высиего образования. Анализируются научные, нормативные, статистические материаль и данные, раскрывающие челевые и функциональные основы аспирантской подготовки в сравнении с положением аспирантуры в прежнее время. Приводятся взгляды на понимание статуса выполняемой аспирантом научно-квалификационной работы. Раскрывается противоречие относительно имеющихся трактовок ответственности вуза за зациту аспирантом диссертации. С опорой на нормативные документы показано отсутствие преференциии у выпускника аспирантуры по сравнению с другими уровнями образования. Анализируются причины снижения продуктивности работы аспирантуры исходя из учета характеристик современного контингента аспирантов. Раскрываются особенности предлагаемьх ученыли диссертационного и образовательного (квалификационного) подходов к определению суиности, челей и функций аспирантуры.

Ключевые слова: аспирантура, аспирантская подготовка, научная работа, компетениии, эффективность аспирантуры, научно-педагогические кадры, научно-квалификационная работа, кандидатская диссертация, профессиональный стандарт, квалификациониые требования, преподавание в вузе, мотивация обучения, диплом об окончании аспирантуры, ученая степень, подходы к организации аспирантуры.

\section{Sergey Bobryshov, Natalia Dzhegutanova THE MEANINGS, PURPOSE AND FUNCTION} OF THE CONTEMPORARY RUSSIAN GRADUATE SCHOOL: PROBLEM ANALYSIS

The article deals with various aspects of understanding of the modern model of the Russian postgraduate school as a level of higher education. The scientific, normative, statistical materials and data revealing the target and functional basis of postgraduate training are analyzed in comparison with the situation of postgraduate study in the previous time. The views on the understanding of the status of research qualification work performed by a graduate student are given. The contradiction concerning the available interpretations of the responsibility of the University for the defense of a thesis by a postgraduate student is revealed. Based on the normative documents, the absence of preferences among the graduate of graduate students compared to other levels of education is shown. The reasons for the decline in the productivity of graduate school based on the characteristics of the modern contingent of graduate students are analyzed. The features of the dissertation and educational (qualification) approaches to the definition of the essence, goals and functions of the postgraduate study are revealed.

Key words: postgraduate, postgraduate education, scientific work, competences, the effectiveness of the postgraduate school, scientific and pedagogical staff, scientific and qualification work, candidate dissertation, professional standard, qualification criteria, teaching at the University, motivation to study, postgraduate diploma, scientific degree, approaches to the organization of postgraduate.

Bведение / Introduction. Проблема обеспечения эффективности подготовки научно-педагогических кадров в стране не теряет своей актуальности. Проходящие в научных кругах и на самом высоком административном уровне дискуссии свидетельствуют о глубоких противоречиях в понимании ключевых аспектов функционирования аспирантуры, получившей статус третьего уровня высшего образования [1-6; 13-15]. Главная проблема, которую отмечают специалисты относительно современной аспирантуры в России, это методологическая размытость в определении её цели и вычленении специфических функций, сущностно-смысловая конфликтность и критериальная неточность оценки результатов обучения аспирантов. К чему готовить, чему новому и как надо учить молодого человека, который в системе высшего образования до этого обу- 
чался как минимум 5-6 лет (это вопрос о преемственности уровней бакалавриата, магистратуры, аспирантуры), чем этот процесс должен отличаться от традиционной («дофгосовской») модели аспирантуры, что в личностном и профессиональном плане дает аспирантура её выпускнику, какие преимущества он получает по сравнению с предшествующими уровнями образования - вот вопросы, волнующие и современных исследователей, и самих аспирантов.

Maтериалы и методы / Materials and methods. В основу анализа проблемы положены научные, статистические, нормативные, методические и эмпирические материалы, раскрывающие особенности современного понимания аспирантской подготовки и функционирования российской аспирантуры в целом. В работе с материалами на всех этапах исследования использованы методы системного, структурного, функционального и сравнительного анализа и синтеза; теоретического конструирования и прогнозирования.

Результаты и обсуждение / Results and discussion. Напомним, до того как аспирантура стала ступенью высшего образования, она позиционировалась следующим образом: «Аспирантуру можно рассматривать как научно-образовательную систему развития кадрового потенциала высшей школы, основой которой является научное образование в сочетании с профессиональным и общим, предполагающее двойной продукт: научное знание, полученное в результате диссертационного исследования, личностное и профессиональное развитие аспиранта, в первую очередь - развитие способностей к научному творчеству в процессе индивидуальной исследовательской деятельности и взаимодействия с научно-образовательной средой вуза» [6, с. 9]. Обратим внимание, классическая аспирантура прежде всего была ориентирована на подготовку исследователя и написание диссертации. И если раньше выпуск из аспирантуры без подготовленной диссертации и представления её в диссертационный совет (даже если ты демонстрировал личностное и профессиональное развитие) был серьезным поводом к осуждению аспиранта «за бездумно и бесцельно потраченное время, бездарно растранжиренные государственные средства, потраченные на обучение», то сегодня окончание обучения в аспирантуре без защиты диссертации не только не имеет для выпускника никаких последствий, но и буквально предполагается соответствующими федеральными нормативными документами. И хотя образовательный процесс в аспирантуре построен таким образом, что аспиранты весь период обучения (3-4 года) должны работать над своей диссертацией (собирать научный материал, писать статьи, апробировать материалы исследования на конференциях, представлять отдельные части работы для обсуждения на кафедру и т. д.), все же ФГОС ВО узаконивает, что аспирантура - это всего лишь период подготовки кандидатской диссертации, а вот что с ней дальше делать, защищать её или нет, является персональным решением уже самого выпускника аспирантуры.

Но если диплом кандидата наук на повестке дня не стоит, тогда один из ключевых вопросов - это мотивация добросовестного обучения в аспирантуре, сдачи государственных экзаменов и - как итог - получения диплома об окончании аспирантуры. Что это за диплом, что он дает по сравнению, скажем, с дипломом специалитета или магистратуры?

Прежде всего принято считать, что данный диплом открывает дорогу в состав преподавателей вузов. Уточним данный момент. В соответствии со ст. 69 (п. 4.) Федерального закона «Об образовании в Российской Федерации» в аспирантуре реализуются программы подготовки научно-педагогических кадров. Но кто это такие - научно-педагогические кадры? О. А. Юрмашева на основе многоаспектного анализа данной дефиниции в справочно-энциклопедической и научно-педагогической литературе определяет, что «научно-педагогические кадры - основной, постоянно действующий состав высшего учебного заведения, включающий в себя профессорско-преподавательских и научных работников, реализующий такие направления деятельности, как педагогическое и научно-исследовательское, имеющий психолого-педагогические и научные компетенции» [16, с. 47-48]. Итак, выпускник аспирантуры, получив квалификацию «Исследователь. Преподаватель-исследователь», относится к профессорско-преподавательским и научным работникам. Но каковы его преимущества перед специалистами и магистрами? 
С 01.01.2017 г. начал действовать профессиональный стандарт «Педагог профессионального обучения, профессионального образования и дополнительного профессионального образования», позволяющий оценить профессиональные перспективы выпускника аспирантуры. И, как можно увидеть, карьерных преференций аспиранту-выпускнику он не дает. В обобщенных трудовых функциях (п. 3.9.) «Преподавание по программам бакалавриата, специалитета, магистратуры и ДПП» обозначено единое требование к образованию - высшее, где аспирант находится в одной «линейке» со специалистом и магистром; особые условия допуска к работе и к специалисту, и к магистру, и к аспиранту в должности доцента также одни и те же - ученая степень (звание) [10]. Практически та же самая ситуация и в вопросе возможности занятия должностей в вузе. Требования квалификационного справочника к лицам, претендующим на занятие той или иной преподавательской должности в высшей школе (должности профессорско-преподавательского состава), свидетельствуют, что без ученой степени можно рассчитывать только на должности ассистента, преподавателя или же старшего преподавателя. При этом в перечне требований к квалификации для занятия данных должностей совсем не обязателен диплом об окончании аспирантуры, равно как и квалификация «преподаватель-исследователь». Наличие данного диплома лишь освобождает от необходимости иметь предварительный стаж работы в образовательной организации для претендента на должности ассистента и преподавателя - не менее 1 года, а старшего преподавателя - 3 года, что, по сути, весьма некритично [9].

Ну а что с должностью научного работника? В проекте профстандарта «Научный работник (научная, научно-исследовательская деятельность) » для всех должностей начиная с младшего научного сотрудника и заканчивая главным научным сотрудником разницы, какое у тебя высшее образование - специалитет, магистратура или аспирантура, - по-прежнему нет. А вот для занятия должности от старшего научного сотрудника и выше уже необходима ученая степень как минимум кандидата наук [11]. Следовательно, данный стандарт опять не дает ничего аспиранту, закончившему аспирантуру, получившему соответствующий диплом, но не защитившему диссертацию. Вот и получается, что спрос на аспирантуру сегодня во многом определяется тем, что она как бы предполагает учёную степень, которая, в свою очередь, «становится атрибутом социального престижа», не связанного порой ни с дальнейшей преподавательской, ни с исследовательской деятельностью. И вполне понятно, что после аспирантуры научными сотрудниками желают работать всего порядка $17 \%$ выпускников. Т. е. парадоксальность российской ситуации, как отмечают специалисты, заключается в росте спроса на наличие учёной степени при одновременном падении спроса на рабочие места в сфере науки. А как иначе, если в большинстве случаев продукт интеллектуального научного труда, особенно в гуманитарной сфере, у нас не находит должной реализации, при этом для государственного исследовательского сектора еще типичны и довольно низкие зарплаты [15].

Соответственно вышесказанному, «горячие» споры в обсуждении современной аспирантуры касаются статуса выполняемой аспирантом научно-квалификационной работы (НКР). Ещё в 2017 году прежнее Минобрнауки РФ предлагало сделать обязательной защиту диссертаций для аспирантов. О чем речь? Может, о том, чтобы «напугать» аспирантов и научных руководителей предстоящей дополнительной экспертизой подготовленной работы еще и на уровне диссоветов? В данной связи отметим, что в соответствующем ФГОС ВО к выполненной научно-квалификационной работе аспиранта предъяв.яются те же требования, что и к диссертации. Так, по итогам представления научного доклада об основных результатах подготовленной НКР (диссертации) организация дает заключение, составляемое в соответствии с пунктом 16 Положения о присуждении ученых степеней (утверждено постановлением Правительства Российской Федерации от 24 сентября 2013 г. № 842). Следовательно, вопрос центрируется не на качестве НКР, с которой аспирант завершает обучение. Вполне очевидно, что здесь федеральное Министерство волнует 
(и не без основания) фиксируемое в последние годы валовое снижение количества защищаемых аспирантами научных работ практически по всем специальностям. Некоторые это оббъясняют повышением требовательности к качеству защит, но признаем, что падение защищаемости за последние 15 лет более чем в два раза (удельный вес защитивших диссертацию среди выпусков аспирантуры по всем отраслям науки в 2000 году составлял по очной форме $-29,6 \%$, а по заочной $-32,0 \%$, а уже в 2016 году - 15,5\% и 11,7\% соответственно) [7] свидетельствует также и о том, что реализуемые программы аспирантуры при существующих требованиях не могут быть признаны продуктивными.

Можно, конечно, вспомнить, что и раньше не всё было гладко. Выпускники прежней аспирантуры тоже не обязательно заканчивали её защитой диссертации. Диплом о присуждении учёной степени был определенным бонусом для тех, кто «умудрился» защититься «в срок». И этот срок, в течениие которого выпускник аспирантуры призван был защититься, чтобы подтвердить успешность своего обучения, в разные времена варьировался от месяца до двух-трех лет. Соответственно, еще несколько лет назад в прежней академической системе по отношению к аспирантуре существовали так называемые показатели эффективности: 25 \% (от количества выпускников для академий) и $30 \%$ (для университетов) защитивших диссертации в установленный срок. Эти нормы сегодня не действуют, но, как показывает практика, это не значит, что эффективность работы аспирантуры со стороны учредителей вузов стала оцениваться иначе; многие вузы по-прежнему в качестве показателя эффективности предоставляют в отчетах по государственному заданию сведения о количестве защитивших диссертации аспирантов. И здесь нельзя не зафиксировать глубинное противоречие: с одной стороны, принимая абитуриентов в аспирантуру, вуз фактически берет на себя ответственность выполнить требования ФГОС - в процессе подготовки сформировать у аспиранта требуемые компетенции, обеспечить написание им научно-квалификационной работы должного качества (качества диссертации на соискание степени кандидата наук), и, как итог, при успешной сдаче государственных экзаменов выдать диплом, удостоверяющий выполнение указанных требований. По большому счету - всё, на этом обязательства вуза перед аспирантом выполнены! Но как же быть с последующей защитой диссертации в диссертационном совете? Кто за это должен отвечать? Кто и на каких условиях поведет аспиранта дальше? Ведь ученый в нашей стране (и научный потенциал страны) определяется по-прежнему наличием у него соответствующей ученой степени. Да и некоторые должности, как это было показано выше, без ученой степени не получишь. Так что, по сути, учредитель справедливо упорствуют в сохранении критерия «количество защищенных диссертаций» при оценке эффективности работы аспирантуры. Другой вопрос, должно ли от вуза требовать нести ответственность за два-три года жизни и работы выпускника аспирантуры после её успешного окончания (диплом же выдан). Может ли (должен ли) вуз нести ответственность за то, найдет ли бывший аспирант моральные (при представлении уже одобренной в «своём» вузе диссертации в «чужой» совет там нередко заставляют её переделывать чуть ли не наполовину под вкусы именно тех, кто заседает в этом совете) и материальные средства (весьма немалые) на защиту диссертации? Это и вопрос, в каких условиях вузы будут обеспечивать реализацию данного критерия, тем самым доказывая свою эффективность.

Необходимость новых подходов к организации и оценке работы аспирантуры продиктована не в последнюю очередь и изменением возрастного состава абитуриентов. В аспирантуру массово пришло поколение молодых людей, чьё формирование проходило в новых исторических, социально-экономических и общественно-политических условиях. По сравнению со сложившимся в прежнее время образом научного работника «это молодежь с иной системой ценностей, с иными жизненными планами, значительно дифференцированная по социокультурным и материальным характеристикам, социальной активности и мотивации научной деятельности» $[6, \mathrm{c.} 3]$. По сведениям Росстата, в РФ в среднем 60 \% аспирантов поступают в аспирантуру «с вузовской 
скамьи», не имея опыта работы и не опробовав на практике свои знания, полученные ранее в вузе, не обобщив их в режиме профессиональных дискуссий и не проблематизировав в реальных ситуациях. Причем значение этого показателя практически не меняется с 2000 г. [7; 12].

И это вопрос не только профессиональной состоятельности и способности осуществить зрелое научное исследование. Анализ мотивационных предпочтений поступающих в аспирантуру свидетельствует, что, наряду с ожиданием карьерных перспектив, стремлением к саморазвитию и самореализации, желанием продолжить обучение по профессии, возможностью преподавать, стремлением повысить свой статус и увеличить доходы, получить возможность льготных публикаций статей, поступление в аспирантуру для многих молодых людей весьма часто является хорошей возможностью решения разнообразных личностных проблем и желаний: остаться после окончания вуза в городе, не покидать университетскую среду, не пойти в армию, попробовать за время обучения найти высокооплачиваемую работу и т. д. По данным социологических исследований, более 40 \% молодых людей, поступивших в аспирантуру сразу после окончания вузов, либо не собираются работать в будущем по профессии, связанной с профилем диссертации, либо вообще еще не определились со своими профессиональными намерениями [12, с. 12]. При этом доля так называемого «балласта» - лиц, мотивы которых в принципе не соответствуют целям аспирантского образования, - стабильно составляет около 20 \%. [1]. То есть мотивация поступления в аспирантуру значительного количества аспирантов не связана с развитием исследовательских компетенций, серьезным самообразованием, написанием и успешной защитой диссертации. К этому зачастую добавляются и сопутствующие трудности: совмещение работы и обучения в аспирантуре, при этом работы не всегда по специальности (при мизерной стипендии мало кто может позволить себе не работать, а у аспирантов-заочников другой альтернативы в принципе не существует), необходимость самофинансирования своего исследования и участия в научных конференциях (актуально практически для всех), сложности с подготовкой и публикацией статей в журналах из списка ВАК, защита диссертации в другом городе (в условиях сокращения численности диссоветов это становится рядовым явлением), неопределенные трудовые перспективы, трудные семейные обстоятельства и др. жизненные моменты $[1 ; 2 ; 5 ; 8 ; 12]$.

$\mathrm{Bcё} \mathrm{это} \mathrm{также} \mathrm{многократно} \mathrm{усложняет} \mathrm{и} \mathrm{существенно} \mathrm{снижает} \mathrm{продуктивность} \mathrm{как} \mathrm{образо-}$ вательной составляющей аспирантской подготовки, так и подготовки диссертации. Как следствие демонстрируемый многими молодыми исследователями недостаточный уровень культуры научно-исследовательской деятельности, отсутствие практического опыта в избранной сфере профессиональной деятельности соединяются с неспособностью - из-за отсутствия должной мотивации напряженно заниматься своим образованием и вести научную работу. Это является частой причиной того, что аспиранты, изначально горячо берущиеся за свои исследования, вскоре начинают «остывать» под гнётом учебного процесса (которого они уже «наелись» в предшествующие 6-7 обучения в вузе), а вскоре и отодвигают свои диссертации на второй-третий план, уповая, что времени впереди ещё много, сдадут все экзамены и зачеты, тогда и к исследованию вернутся. Некоторые все же возвращаются, но уже просто не успевают добиться требуемого качества и подлинной научной ценности диссертационного исследования, в результате чего оно часто имеет выраженный «ученический» характер. Ну, а часть оказываются просто не в состоянии написать работу и досрочно завершают своё обучение. Так, по данным статистических исследований, в РФ в среднем за последние годы показатель досрочно отчислившихся или отчисленных из аспирантуры составляет $38 \%$. А в 2016 году из аспирантуры в целом досрочно было отчислено более половины (51\%) от числа поступивших в том году [7]. Факторы, оказывающие влияние на досрочное отчисление аспирантов, не меняются: 80 \% отчисленных без представления диссертации - это аспиранты заочной формы обучения, и формальные причины их отчисления связаны в первую очередь с изменением профессиональных интересов, семейного положения, но, по сути, с невозможностью справляться с нагрузкой - интеллектуальной и материальной, что отягощается потерей мотивации, а также пониманием туманных перспектив «дойти до совета». 
Так каковы возможные направления развития и дальнейшего институционального оформления аспирантуры?

В условиях курса на интеграцию науки, практики и образования в дискуссионном поле о сущности, целях и функциях аспирантуры сформировались два подхода, которые условно определяются как диссертационный и образовательный (квалификационный). Сторонники первого подхода, являющиеся оппонентами существующего ФГОС, предназначение аспирантуры видят в научной работе, подготовке и защите диссертации. Образовательную же часть программы с её зачетами, экзаменами, практикой и др. с их точки зрения надо упростить, так как она лишь отвлекает аспирантов от диссертации. Для апологетов второго направления важнее подготовить узнаваемого в научном сообществе специалиста, свободно ориентирующегося и в «своей», и в смежных областях науки, с широким набором определенных исследовательских, творческих, инновационных, коммуникативных и др. компетенций и качеств, способного как к научной, так и преподавательской деятельности. При этом написание диссертации хоть и важная, но сопутствующая задача. Однако посмотрим на этот вопрос шире.

Представляется более взвешенной и продуктивной точка зрения, в соответствии с которой упомянутые подходы не должны рассматриваться как простая альтернатива - в аспирантуре необходима и серьезная научная работа, и солидная образовательная подготовка [3; 14]. Как отмечает М. А. Капшутарь, «... эффективность подготовки аспирантов следует рассматривать в двух аспектах - академическом (качество и результаты образовательной подготовки) и научном (качество и результаты научно-исследовательской деятельности аспирантов)» [3]. Первый аспект определяется уровнем сформированности универсальных, общепрофессиональных и профессиональных компетенций, второй - достигнутыми показателями научной активности аспиранта, к которым относятся: количество публикаций в рецензируемых научных изданиях, выступления на конференциях и семинарах разного уровня, участие в научных олимпиадах и конкурсах аспирантских работ, а также подготовленный в срок текст диссертации [3]. Возможно ли это? Думается да, если вопросом дискуссии станет не перетягивание каната в сторону диссертации или образовательной подготовки, и даже не вопрос о содержании этой подготовки, её объёмах, способах реализации и исследовательского наполнения, а вопрос о целях и функциях образовательной программы в аспирантуре в целом.

Исходя из того, что именно за счет упомянутой интеграции науки, практики и образования должна быть повышена эффективность новой аспирантуры, совершенно справедливо подумать о вариативности конечного продукта такой аспирантуры. Вариативности в плане достижения определенной квалификационной «заточенности» выпускника аспирантуры под работу в конкретных сферах и на решение каких-то конкретных задач, с учётом планируемой дальнейшей профессиональной траектории (производственной или академической). В частности, Б. И. Бедный называет примеры следующих двух актуальных направлений для организации целевой профессиональной подготовки специалистов в аспирантуре:

1) подготовка кадров для индустрии. Предусматривает адресную подготовку высококвалифицированных специалистов для наукоёмких промышленных предприятий. Итогом обучения может стать присуждение так называемой профессиональной степени, даваемой по результатам защиты практико-ориентированного проекта, значимого для конкретной области профессиональной деятельности;

2) подготовка кадров для науки и высшей школы. Здесь центральной задачей является воспроизводство кадрового потенциала науки и высшей школы путем реализации оптимально выстроенных академических программ, ориентированных на подготовку научных работников и вузовских преподавателей, решивших делать академическую карьеру. И вот как раз для выпускников аспирантуры, планирующих развивать карьеру в сфере науки и высшей школы, важнейшим этапом подтверждения их профессиональной квалификации и должна стать защита кандидатской диссертации [1, с. 9-10]. 
Примерно такое же предложение высказывает и В. С. Сенашенко, рассуждающий о возможности создания исследовательской и профессиональной аспирантуры, каждая из которых будет иметь свою образовательную траекторию:

- $\quad$ исследовательская - это академическая аспирантура с традиционной академической направленностью, исследовательской подготовкой и написанием кандидатской диссертации;

- профессиональная - это практико-ориентированная (технологическая) аспирантура профессиональной направленности. Профессиональная аспирантура, как отмечает автор, в этом случае могла бы допустить менее высокие требования к диссертации, но при этом должна отличаться более высокими требованиями к профессиональной квалификации выпускника, а образовательная программа призвана стать междисциплинарной. Это, подчеркивает ученый, особенно важно в условиях сетевой реализации образовательных программ, дающей возможность привлечь работодателей в области экономики, менеджмента, сферы обслуживания и пр. [13, с. 37].

Обозначенные подходы актуализируют вопрос о содержательном наполнении квалификационных характеристик выпускника аспирантуры в зависимости от планируемой сферы деятельности. Но какими бы они ни были, исследователи $[4 ; 15]$ обращают внимание на несколько базовых функциональных направлений работы аспирантуры исходя из понимания её главных задач: обеспечение самоактуализации личности, стремления к возможно более полному выявлению, раскрытию и развитию своих личностных возможностей и способностей; обучение способам принимать нестандартные научные решения, креативным и аналитическим методам создания инноваций, нахождения новых идей, в том числе на стыке разных наук; обучение эффективным технологиям мышления, в частности методам концептуального мышления; развитие способности создавать интеллектуальную собственность и осуществлять её трансфер в нематериальные (и материальные) активы, генерировать и разрешать проблемы и задачи глобального характера; обучение навыкам и компетенциям разнообразного взаимодействия, проявлять гибкость на пути к цели, выдерживать критику, пренебрежение, не поддаваясь постороннему влиянию и не паникуя; обучение техникам личной работы над собой, методам перехвата инициативы и манипулирования, работы в условиях дефицита времени и ресурсов; обучение способам находить источники инвестиций для своей деятельности; обучение способам подтверждения своей значимости и компетенции во внешней среде, нахождения своего места среди ученых, занимающихся данной проблемой.

В целом это должно стимулировать аспирантуру к переходу от подготовки просто компетентных исполнителей (согласно ФГОС ВО) к подготовке творцов и создателей новых решений, концепций и систем.

Заключение / Conclusion. Это лишь небольшая часть проблем, с которыми сегодня сталкиваются субъекты образовательного процесса на 3-й ступени ВО. Заметим, что в целом аспирантская подготовка в ее сегодняшнем статусе не противоречит по смыслу идеалу «старой» аспирантуры, даже с её показателями эффективности. Предоставляя солидный образовательный базис, а таюже бесценный опыт научно-исследовательской работы, она дает молодому ученому возможность реализоваться как специалисту с инновационным личностным и профессиональным профилем, будучи даже не в статусе кандидата наук. Хотя признаем, что диплом об окончании аспирантуры должен стать более весомым и значимым. При этом стоит также признать, что идея о том, что $100 \%$ научно-квалификационных работ выпускников аспирантуры будут обладать научной новизной следует отнести к области весьма вредных фантазий.

Уровень культуры научно-исследовательской деятельности современных аспирантов, а также уровень их мотивации и ее направленность требуют специального внимания и реагирования. В сложившейся ситуации при оценке эффективности работы аспирантуры ограничиться констатацией факта написания научно-квалификационной работы, сдачи кандидатских и государственных 
экзаменов в корне неверно. Но и возврашение к прошлому, каким бы правильным это прошлое нам ни казалось, не может быть определено как развитие. Апелляция к прошлому скорее свидетельствует о том, что реформирование образовательной системы без учета внешних факторов (падение престижа научной работы и ученого, нестабильность и субъективность работы диссоветов, серьезные материальные затраты аспирантов и др.) нивелируют усилия, направленные на поддержку молодежи к непрерывному образованию и интеграцию науки, практики и образования в системе подготовки научно-педагогических кадров. Необходима комплексная система оценки работы аспирантуры и качества подготовки аспирантов, учитывающая цели и потребности всех участников данного процесса.

Если мы хотим не просто увеличить количество «остепененных» молодых людей, а создать в стране класс молодых ученых, способных в целом повлиять на изменения в экономической и социальной сферах жизни, то аспиранта необходимо не просто нацеливать на написание диссертации как проект личностного роста, его необходимо в полном смысле образовывать, создавая основу для роста его ответственности за взятые перед государством обязательства, его академической культуры, составной частью которой является понимание научной и творческой свободы как ответственности за сделанный выбор.

\section{ЛИТЕРАТУРА И ИНТЕРНЕТ-РЕСУРСЫ}

1. Бедный Б. И. Новая модель аспирантуры: PRO ET CONTRA // Высшее образование в России. 2017. № 4. С. 5-16.

2. Иванов А. Ю. Положительные и отрицательные аспекты обучения в аспирантуре // Проблемы и перспективы развития образования в России. 2015. № 34. С. 233-237.

3. Капшутарь М. А. Качество подготовки аспирантов и эффективность современной аспирантуры: проблема поиска новых показателей // Современные наукоемкие технологии. 2016. № 7-1. С. 132-136. URL: http://top-technologies.ru/ru/article/view?id=36075 (дата обращения: 13.07.2018).

4. Кармазинский А. Н. Аспирантура: проблемы и пути их решения // Современные проблемы науки и образования. Электронный научный журнал. 2012. № 6. URL: http://science-education.ru/ru/article/ view?id=7614 (дата обращения: 13.07.2018).

5. Мкртчян Е. Р. Воспроизводство научно-педагогических кадров в вузах города Волгограда. Результаты опроса аспирантов // Alma Mater (Вестник высшей школы). 2014. № 10. С. 37-43.

6. Непомнящая Л. В. Аспирантура как научно-образовательная система развития кадрового потенциала высшей школы: дис. ... канд. пед. наук: 13.00.08. Краснодар, 2005. 158 с.

7. Подготовка научных кадров высшей квалификации в России. 2017: Информационно-статистический материал «Статистика науки и образования» / Е. В. Березина, К. В. Лебедев, Н. А. Плужнова, Л. В. Прохорова, А. В. Федин. М.: ФГБНУ НИИ РИНКЦЭ, 2017. 171 с.

8. Портрет современного российского аспиранта / С. К. Бекова, И. А. Груздев, З. И. Джафарова, Н. Г. Малошонок, Е. А. Терентьев. М.: НИУ ВШЭ, 2017.60 с. (Современная аналитика образования. № 7 (15)).

9. Об утверждении Единого квалификационного справочника должностей руководителей, специалистов и служащих: Приказ Минздравсоцразвития РФ от 11.01.2011 № 1н. Раздел «Квалификационные характеристики должностей руководителей и специалистов высшего профессионального и дополнительного профессионального образования» [Электронный ресурс] // СПС «КонсультантПлюс».

10. Об утверждении профессионального стандарта «Педагог профессионального обучения, профессионального образования и дополнительного профессионального образования»: Приказ Минтруда России от 08.09.2015 № 608н [Электронный ресурс] // СПС «КонсультантПлюс».

11. Об утверждении профессионального стандарта «Научный работник (научная (научно-нсследовательская) деятельность)»: Проект Приказа Министерства труда и социальной защиты РФ (подготовлен Минтрудом России 05.09.2017) [Электронный ресурс] // СПС «КонсультантПлюс».

12. Российская аспирантура в поисках новых возможностей развития: Информационно-аналитический бюллетень № 3 / Л. Г. Зуббова, Е. В. Аржаных, О. Н. Андреева, О. А. Антропова. М., 2011. 90 с. URL: http://innoedu.ru/docs/actual/inf3_2011.pdf (дата обращения: 12.07.2018). 
13. Сенашенко В. С. Проблемы организации аспирантуры на основе ФГОС третьего уровня высшего образования // Высшее образование в России. 2016. № 3. С. 33-43.

14. Серова Т. В. Комплексная оценка эффективности аспирантуры в области точных и естественных наук // Инновации в образовании. Вестник Нижегородского университета им. Н. И. Лобачевского. 2011. № 3(1). C. 19-25.

15. Шестак В. П., Шестак Н. В. Аспирантура как третий уровень высшего образования: дискурсивное поле // Высшее образование в России. 2015. № 12. С. 22-34.

16. Юрмашева О. А. Понятие «научно-педагогические кадрыр: системно-структурный анализ // Педагогическое образование и наука. № 8. 2009. C. 47-50. URL: http://library.ua/m/articles/view/Понятие-научно-педагогические-кадры-системно-структурный-анализ (дата обращения: 12.07.2018).

\section{REFERENCES AND INTERNET RESOURCES}

1. Bednyi B. I. Novaya model' aspirantury: PRO ET CONTRA (New model of postgraduate study: PRO ET CONTRA) // Vysshee obrazovanie v Rossii. 2017. No 4. P. 5-16.

2. Ivanov A. Yu. Polozhitel'nye i otritsatel'nye aspekty obucheniya v aspiranture (Positive and negative aspects of postgraduate education) // Problemy i perspektivy razvitiya obrazovaniya v Rossii. 2015. No 34. P. 233-237.

3. Kapshutar' M. A. Kachestvo podgotovki aspirantov i effektivnost' sovremennoi aspirantury: problema poiska novykh pokazatelei (The quality of postgraduate training and the effectiveness of modern graduate school: the problem of finding of new indicators) // Sovremennye naukoemkie tekhnologii. 2016, No 7-1. P. 132-136, URL: http://top-technologies.ru/ru/article/view?id=36075 (data obrashcheniya: 13.07.2018).

4. Karmazinskii A. N. Aspirantura: problemy i puti ikh resheniya (Postgraduate studies: problems and ways of their solution) // Sovremennye problemy nauki i obrazovaniya. Elektronnyi nauchnyi zhurnal. 2012. No 6. URL: http://science-education.ru/ru/article/view?id=7614 (data obrashcheniya: 13.07.2018).

5. Mkrtchyan E. R. Vosproizvodstvo nauchno-pedagogicheskikh kadrov v vuzakh goroda Volgograda. Rezul'taty oprosa aspirantov (Reproduction of scientific and pedagogical personnel in the universities of Volgograd. Results of the survey of graduate students) // Alma Mater (Vestnik vysshei shkoly). 2014. No 10. P. 37-43.

6. Nepomnyashchaya L. V. Aspirantura kak nauchno-obrazovatel'naya sistema razvitiya kadrovogo potentsiala vysshei shkoly (Postgraduate study as a scientific and educational system of development of human resources of higher school), Diss. ... kand. ped. nauk: 13.00.08, Krasnodar, 2005, 158 p.

7. Berezina E. V. Podgotovka nauchnykh kadrov vysshei kvalifikatsii v Rossii. 2017. (Training of highly qualified scientific personnel in Russia. 2017) / E. V. Berezina, K. V. Lebedev, N. A. Pluzhnova, L. V. Prokhorova, A. V. Fedin. Informatsionno-statisticheskii material «Statistika nauki i obrazovaniya». M., 2017. 171 p.

8. Bekova S. K. Portret sovremennogo rossiiskogo aspirant (Portrait of a modern Russian graduate student) / S. K. Bekova, I. A. Gruzdev, Z. I. Dzhafarova, N. G. Maloshonok, E. A. Terent'ev. M., 2017, 60 p. (Sovremennaya analitika obrazovaniya, No.7 (15)).

9. Ob utverzhdenii «Edinogo kvalifikatsionnogo spravochnika dolzhnostei rukovoditelei, spetsialistov i sluzhashchikh»: Prikaz Minzdravsotsrazvitiya RF ot 11.01.2011 № 1n. Razdel «Kvalifikatsionnye kharakteristiki dolzhnostei rukovoditelei i spetsialistov vysshego professional'nogo i dopolnitel'nogo professional'nogo obrazovaniya» (On approval of the «Unified qualification directory of positions of managers, specialists and employees»: Order of the Ministry of health and social development of the Russian Federation of 11.01.2011 № 1n. Section «Qualification characteristics of positions of managers and specialists of higher professional and additional professional education») [Elektronnyi resurs] // SPS «Konsul'tantPlyus».

10. Ob utverzhdenii professional'nogo standarta «Pedagog professional'nogo obucheniya, professional'nogo obrazovaniya i dopolnitel'nogo professional'nogo obrazovaniya»: Prikaz Mintruda Rossii ot 08.09.2015 № $608 \mathrm{n}$ (About the approval of the professional standard «The Teacher of professional training, professional education and additional professional education»: Order of Ministry of labor of Russia of 08.09.2015n № 608n) [Elektronnyi resurs] // SPS «Konsul'tantPlyus». 
11. Ob utverzhdenii professional'nogo standarta «Nauchnyi rabotnik (nauchnaya (nauchno-issledovatel'skaya) deyatel'nost')»: Proekt Prikaza Ministerstva truda i sotsial'noi zashchity RF (On approval of the professional standard «Researcher (scientific (research) activity)»: Draft Order of the Ministry of labour and social protection of the Russian Federation) (podgotovlen Mintrudom Rossii 05.09.2017) [Elektronnyi resurs] // SPS «Konsul'tantPlyus».

12. Zubova L. G. Rossiiskaya aspirantura v poiskakh novykh vozmozhnostei razvitiya (Russian postgraduate study in search of new development opportunities) / L. G. Zubova, E. V. Arzhanykh, O. N. Andreeva, O. A. Antropova: Informatsionno-analiticheskii byulleten' № 3. M., 2011. 90 s. URL: http://innoedu.ru/ docs/actual/inf3_2011.pdf (data obrashcheniya: 12.07.2018).

13. Senashenko V. S. Problemy organizatsii aspirantury na osnove FGOS tret'ego urovnya vysshego obrazovaniya (Problems of organization of postgraduate study on the basis of the GEF of the third level of higher education) // Vysshee obrazovanie v Rossii. 2016. No 3. P. 33-43.

14. Serova T. V. Kompleksnaya otsenka effektivnosti aspirantury v oblasti tochnykh i estestvennykh nauk, Innovatsii v obrazovanii (Comprehensive assessment of the effectiveness of postgraduate studies in the field of exact and natural Sciences) // Vestnik Nizhegorodskogo universiteta im. N. I. Lobachevskogo. 2011. No 3(1). P. 19-25.

15. Shestak V. P., Shestak N. V. Aspirantura kak tretii uroven' vysshego obrazovaniya: diskursivnoe pole (Graduate school as the third level of higher education: the discursive field) // Vysshee obrazovanie v Rossii. 2015. No 12. P. 22-34.

16. Yurmasheva O. A. Ponyatie «nauchno-pedagogicheskie kadry»: sistemno-strukturnyi analiz (The concept of «scientific and pedagogical personnel»: system-structural analysis) // Pedagogicheskoe obrazovanie i nauka. 2009. No 8. S. 47-50. URL: http://library.ua/m/articles/view/Ponyatie-nauchno-pedagogicheskiekadry-sistemno-strukturnyi-analiz (data obrashcheniya: 12.07.2018).

\section{СВЕДЕНИЯ ОБ АВТОРАХ}

Бобрышиов Сергей Викторович, доктор педагогических наук, профессор, заведующий кафедры воспитания, социализации и развития личности, ГБОУ ВО «Ставропольский государственный педагогический институт». E-mail: svbobrishov@yandex.ru

Джегутанова Наталья Ивановна, кандидат педагогических наук, доцент кафедры иностранных языков, начальник учебно-методического управления ГБОУ ВО «Ставропольский государственный педагогический институт». E-mail: mart_64@bk.ru

\section{INFORMATION ABOUT AUTHORS}

Bobryshov Sergey, Doctor of Pedagogical Sciences, Professor, Head of Department of Education, Socialization and Development of the Individual, State-financed educational institution of higher education «Stavropol State Pedagogical Institute» (SSPI). E-mail: svbobrishov $a y$ yandex.ru

Dzhegutanova Natalia, Candidate of Pedagogical Sciences, Associate Professor of Foreign Languages, Head of Educational and Methodical Department, State-financed educational institution of higher education «Stavropol State Pedagogical Institute» (SSPI). E-mail: mart_64@bk.ru 